Stêvenis Moacir Moura da Fonseca Andréa Pereira da Silva Emanuel Ferreira Leite

Artigo recebido em: 29/04/2017 Artigo aprovado em: 18/06/2018 


\title{
Fotoetnografia: Uso e Possibilidades como Método de Pesquisa em Administração
}

\author{
Photoethnography: Uses and Possibilities as a Research \\ Method in Administration
}

\author{
Stêvenis Moacir Moura da Fonseca* \\ Andréa Pereira da Silva** \\ Emanuel Ferreira Leite****
}

\begin{abstract}
Resumo: A fotoetnografia é um método que utiliza a fotografia como narrativa imagética capaz de preservar o dado e convergir para o leitor uma informação cultural a respeito do grupo estudado. O objetivo deste ensaio é discutir o método fotoetnográfico no âmbito da pesquisa em Administração, apresentando conceitos, sua operação e uma reflexão sobre como pode ser utilizado na área. Os parâmetros adotados na realização deste artigo seguiram a linha da antropologia visual, bem como foram utilizados os passos da etnografia, tendo em vista a ausência de protocolo para operação do método especifico na literatura. Dessa maneira, concluiu-se que a fotoetnografia pode representar uma extensão eficaz da etnografia para a consecução de pesquisas em Administração com determinados sujeitos em diferentes locais de interação social.
\end{abstract}

Palavras-chave: Fotoetnografia. Pesquisa qualitativa. Método de pesquisa. Antropologia visual.

Abstract: Photoethnography is a method that uses photography as imagetic narrative able to preserve the data and converge to the reader cultural an information about the study group.

\footnotetext{
* Mestre em Administração/Gestão do Desenvolvimento Local Sustentável pela Universidade de Pernambuco.

** Mestre em Administração/Gestão do Desenvolvimento Local Sustentável UPE.E-mail: andreapsil2@hotmail.com

*** Doutor em Ciências de Engenharia pela Universidade do Porto. Professor da Universidade de Pernambuco - UPE.
} 
The purpose of this essay is to discuss the Photoethnographic method in the context of research in Administration, presenting concepts, its operation and a reflection on how it can be used in the area. The parameters used in this article followed the line of visual anthropology, as well as the steps of ethnography, considering the absence of protocol for operation of the specific method in the literature. Thus, it was concluded that Photoethnography may represent an effective extension of ethnography to achieve the research in Administration with certain subjects in different places of social interaction.

Keywords: Photoethnography. Qualitative research. Research method. Visual anthropology.

\section{Introdução}

A discussão acerca de abordagens qualitativas em pesquisa tem sido cada vez mais frequente, embora a pesquisa quantitativa prevaleça sobre métodos qualitativos na academia (BELK; FISCHER; KOZINETS, 2013). Neste sentido, é imprescindível a exploração de novos conhecimentos e também novos métodos que proporcionem o crescimento e a inovação das organizações. Afinal, uma organização só se desenvolve por meio da constante busca por conhecimento.

O objetivo deste ensaio é discutir o método fotoetnográfico no âmbito da pesquisa em Administração, apresentando conceitos, sua operação e uma reflexão sobre como pode ser utilizado na área. Estudos "que se auto definem como etnográficos têm apresentado um crescimento muito significativo nas publicações especializadas da área" (ROCHA; BARROS, 2006, p. 37). Mesmo assim, uma das possibilidades da pesquisa etnográfica - a fotoetnografia -, em pesquisa bibliométrica nas revistas brasileiras e estrangeiras, bem 
como em anais de congressos, é bastante carente de aplicação na área de Administração. Aprofundando-se sobre seu funcionamento, fica clara uma vasta possibilidade de aplicação do método.

A fotoetnografia é um método que utiliza a fotografia como narrativa imagética capaz de preservar o dado e convergir para o leitor uma informação cultural a respeito do grupo estudado (ACHUTTI, 1997a). Ela é mais comum na antropologia e considera que as imagens fotográficas não devem ser vistas como mero registro da realidade, entendendo que os indivíduos levam consigo crenças e valores que absorvem de sua cultura e de sua sociedade que podem ser representados através da linguagem visual. Nesse sentido, as fotos podem descrever os interesses dos indivíduos no grupo que compartilham a mesma cultura, bem como suas idiossincrasias.

Sendo assim, uma "das vantagens do material fotoetnográfico é que ele expõe ao receptor a etnia em seu momento atual, bem como suas aculturações e transformações" (BONI; MORESCHI, 2007, p. 141-142), ou ainda a obtenção de informações que não seriam capturadas através de entrevistas ou que não foram anotadas em diários de campo (COLLIER JUNIOR, 1973). Em síntese, trata-se de uma documentação histórica das culturas e da sociedade, possibilitando uma melhor compreensão dos processos de transformação de uma sociedade (ACHUTTI, 1997a; BONI; MORESCHI, 2007; COLLIER JUNIOR, 1973).

Quanto às limitações do método, pode-se destacar a necessidade da elaboração de um plano etnográfico prévio, do domínio técnico do equipamento de modo que as imagens possam vir a constituir uma narrativa e também a imersão do pesquisador no universo pesquisado (ACHUTTI, 1997a, 1997b, 2004a, 2004b; 
BONI; MORESCHI, 2007; CAVEDON, 1999; COLLIER JUNIOR, 1973). Evidentemente, como qualquer método qualitativo, não está livre das subjetividades dos sujeitos envolvidos (BONI; MORESCHI, 2007; COLLIER JUNIOR 1973).

Por fim, os parâmetros adotados na realização deste artigo seguiram a linha da antropologia visual, bem como foram utilizados os passos da etnografia, tendo em vista a pouca publicação sobre o tema e a ausência de protocolo para operação do método específico na literatura. Tal fato configura esse método como um campo ainda pouco explorado, particularmente, nas ciências administrativas, consequência do fato de haver poucas pesquisas e ações que utilizam esse método.

Assim, o presente artigo trata-se de um ensaio metodológico que está estruturado em cinco seções, contando com a introdução. A segunda seção conceitua o método de fotoetnografia e operação do método. A terceira seção descreve a operação do método. A quarta seção apresenta o emprego do método, relatando as experiências com o seu emprego e possibilidades nas ciências administrativas; por último, são tecidas as considerações finais.

\section{Conceitos de Fotoetnografia}

Antes de aprofundar no conceito de fotoetnografia, vale a pena entender o que significa etnografia. Essa palavra deriva da combinação do termo grego ethnos - que denota uma pessoa, raça ou grupo cultural - e 'grafia', que significa escrita, representação. Assim, etnografia significa o estudo das culturas (BELK; FISCHER; 
KOZINETS, 2013). Freitas e Leão (2012, p. 214) conceituam bem o termo:

A etnografia é concebida como um método de pesquisa e análise de dados, que se utiliza da descrição densa, significando que o pesquisador conceberá as culturas como teias de significados, frutos da vida em sociedade dos indivíduos, guiadas por seus conjuntos de valores, os quais serão alvo da interpretação do pesquisador, sendo estes conjuntos, mesmo antes, produto das interpretações de sua sociedade.

Uma descrição densa não se trata meramente de descrever minuciosamente os aspectos de uma cultura, mas de entender tudo aquilo que foi observado dentro de um sistema de significados que explique as razões dos comportamentos estudados (PINTO; BARROS, 2008). Freitas e Leão (2012) sustentam que o estudo etnográfico pressupõe a inserção do pesquisador no contexto microscópico observado no sentido de que a vida do grupo seja vista 'de dentro' e por meio dos indivíduos, ou seja, como são constituídos os pensamentos e valores do grupo.

Belk, Fischer e Kozinets (2013) enumeram as principais características do método etnográfico: a) abordagem microscópica de um fenômeno social; b) mapeamento de significados e interpretação das práticas grupais segundo seus membros; c) concepção da realidade como um construto social; d) contato prolongado do pesquisador com o campo; e) utilização de uma variedade de fontes de coleta de dados; f) estudo das interações simbólicas dos indivíduos no contexto do grupo estudado; g) interferência do pesquisador no contexto da pesquisa e engajamento do pesquisador no grupo observado; e h) relação de confiança entre 
o pesquisador e os informantes.

A inclusão das fotografias nos textos etnográficos pode apresentar-se como narração tal qual as falas dos informantes, as descrições ambientais e tantos outros recortes dos dados de campo que contribuem para legitimar as interpretações e análises efetuadas pelos antropólogos. A fotografia permite reviver a situação de campo tal como ela se apresentou, auxiliando na interpretação (GODOLPHIM, 1995). Novaes (2012) aponta que a fotografia aparece como recurso estratégico que se alia ao caderno de campo, permitindo registrar o que dificilmente conseguimos descrever em palavras, seja pela densidade visual daquilo que registramos, seja por seu aspecto mais sensível e emocional.

O apoio da fotografia propicia uma descrição mais completa e detalhada de situações complexas, de ações rápidas. Ela pode, por exemplo, marcar as etapas de um ritual, destacar a posição precisa dos personagens, seus gestos, indumentárias, pondo em evidência aspectos que dificilmente poderiam ser traduzidos claramente apenas pela linguagem escrita (MALINOWSKI, 1985). A imagem fotográfica foi, desde que surgiu, o ponto para onde convergiram múltiplos discursos: “discurso técnico, estético, literário, filosófico, psicanalítico, semiótico, sociológico e antropológico, discursos sobre seus estilos, seus gêneros, seus possíveis usos; discursos daqueles que a faziam e debates que essa imagem suscitava nos meios artísticos" (SAMAIN, 2005, p. 14).

Uma das primeiras sistematizações sobre o uso da fotografia na pesquisa de campo data de 1967, quando John Collier Júnior publica o livro 'Antropologia visual: a fotografia como método de pesquisa' (em português, foi publicado em 1973). Assim 
como na antropologia, a fotografia tem um observador participante que escava detalhes e fareja com seu olhar o alvo e o objeto de suas lentes e de sua interpretação. Nessa linha, o valor da câmera como um instrumento etnográfico é similar ao gravador de áudio: a câmera fornece um traço preciso dos eventos que deixam uma grande liberdade para a interpretação analítica (ANDRADE, 2002). $\mathrm{O}$ emprego da antropologia visual enquanto um recurso narrativo autônomo ajuda a convergir significações e informações a respeito de uma dada situação social.

Achutti (1997b) dialoga com o campo de conhecimento da antropologia visual, estabelecendo semelhanças e diferenças na utilização das imagens para a construção do saber antropológico. Ele procura ressaltar o potencial narrativo das imagens fotográficas utilizadas sob a forma de "narrações visuais e uma construção do sentido graças à imagem. Isso para tornar-se um meio de restituição, uma outra forma de narrar nosso olhar sobre o Outro" (ACHUTTI, 1997b, p. 87). Essas narrações visuais, onde pode situar a fotoetnografia, encerram um sentido por trabalharem com conjuntos e sequências de imagens, possibilitando uma leitura completa, tornando refutável o medo atribuído ao uso da imagem pela abertura de sentidos possíveis. Assim, as fotografias "devem ser objeto de construções sob forma de sequências e de associações de imagens, tendo por objetivo treinar o leitor a praticar outras associações para nelas encontrar uma significação" (ACHUTTI 1997b, p. 117). Neste sentido,

[...] a fotografia apresenta-se como uma forma de descrição e interpretação dos dados obtidos em campo, não apenas como um instrumento de 
coleta de informações a fim de realizar um simples inventário da cultura estudada, constituindo verdadeiros 'textos visuais' que o antropólogo constrói para restituir determinada realidade. A fotografia deve ser encarada como a materialização de um olhar, o discurso de um olhar (ACHUTTI, 1997b, p. 111).

Com essa leitura, Achutti (1997a, p. 14) desenvolveu o método que ele denominou de fotoetnografia; tal método consiste "no uso da fotografia como uma narrativa imagética capaz de preservar o dado e convergir para o leitor uma informação cultural a respeito do grupo estudado". Através de uma abordagem descritiva, em que a principal forma de narrar é o uso de imagens, através de um exercício de uma antropologia visual utilizando a técnica fotográfica - fotoetnografia - o autor busca investigar os elementos com os quais os sujeitos interagem. O referido autor reforça:

[...] o domínio técnico aliado ao olhar treinado [...] pode levar à construção de um trabalho fotoetnográfico que venha a ser relevante, não só como mais uma das técnicas de pesquisa de campo, mas também como uma outra forma narrativa, que somada ao texto etnográfico, venha a enriquecer e dar mais profundidade à difusão dos resultados obtidos (ACHUTTI, 1997a, p. 64).

Assim, Luiz Eduardo Achutti observa no trabalho fotoetnográfico a necessidade de fotografar pensando na narrativa visual ou fotográfica, na sequência de informações visuais a ser apresentada (e vista) e como um importante modelo de apresentação do trabalho de investigação - observando que o pesquisador deve ter em mente: (a) o formato no qual irá apresentar seu resultado; 
(b) a finalidade para a qual se destinará; (c) as possíveis formas de acesso; além de (d) um planejamento a respeito da execução das fotografias.

Se, desde o princípio do trabalho de campo, o pesquisador fotógrafo não tiver em mente a paginação final (ou a montagem da exposição fotográfica, conforme o caso), o resultado de seu trabalho sofrerá desta falta de planificação, pois uma narrativa visual que pretenda utilizar a fotografia deve ser fruto de um longo processo de construção [...] de uma descrição visual (ACHUTTI, 2004a, p. $3-4)$.

Em contrapartida, é importante lembrar que o uso dos métodos visuais não é uma panaceia para todos os problemas etnográficos e nem o ponto de partida para o início das descobertas etnográficas. Todavia, a fotoetnografia pode mostrar tendências, permitindo que os olhos façam os trabalhos que, muitas vezes, eram realizados somente pela linguagem escrita nos estudos etnográficos (PROSSER, 1998).

Com a fotoetnografia, pode-se construir textos imagéticos a respeito da cultura do outro e fazer construções descritivas e narrativas. Narrativas no sentido amplo, como "conjunto organizado de significantes, cujos significados constituem uma história [...] que deve se desenrolar no tempo; uma narrativa visual que venha enriquecer, trazer novos ângulos, com uma outra grafia" (ACHUTTI, 1997b, p. 77). Entretanto, não existe protocolo definido para a operação do método fotoetnográfico. Dessa forma, na próxima seção, será descrita utilizando formas da etnometodologia, com adaptações dos autores para análise imagética. 


\section{Operação do Método Fotoetnográfico}

Esta seção resgata o método etnográfico a fim de ajudar a desenvolver a fotoetnografia. A base da etnometodologia está nas atividades práticas pelas quais os atores produzem e reconhecem as circunstâncias em que estão inseridos, devido ao sentido que as práticas têm para eles.Assim, oprincipal objetivo etnometodológicoé investigar os processos de realização das atividades, preocupando-se com o comportamento dos membros envolvidos no contexto de uma coletividade, um grupo ou uma organização (HERITAGE, 1987). Ten-Have (2004) afirma que a pesquisa etnometodológica deve ser dividida em duas fases: a primeira, refere-se ao entendimento das atividades em estudo, focando-se a criação de sentido das práticas atribuídas pelos atores sociais que as compartilham; e a segunda, à análise dos métodos utilizados na primeira fase.

Arnould e Wallendorf (1994) elencaram as principais etapas da pesquisa etnográfica: 1) Coleta sistemática de dados no contexto natural das interações do grupo estudado; 2) observação participante do pesquisador durante longos períodos em um contexto cultural específico; 3) produção de interpretações confiáveis sobre o público estudado para os informantes e para o público que utilizará o estudo; e 4) uso de várias fontes de dados. Rocha e Barros (2006) complementam apontando como características do método etnográfico: 1) ênfase na exploração da natureza de um fenômeno social particular; 2) entrevistas em profundidade; 3) observação participante; 4) investigação em detalhe; 5) perspectiva microscópica; e 6) interpretação de significados e práticas sociais como expressos nos discursos dos informantes. 
Quanto à questão do tempo prolongado de imersão no campo, Belk, Fischer e Kozinets (2013) sugerem que não há como precisar o tempo necessário para que se alcance a saturação teórica. A saturação teórica está relacionada à compreensão do fenômeno social estudado pelo pesquisador, pois a "pesquisa etnográfica é baseada na imersão no campo onde ocorre determinado fenômeno por uma quantidade de tempo suficiente para se desenvolver uma compreensão profunda deste fenômeno, grupo ou cultura" (BELK; FISCHER; KOZINETS, 2013, p. 70). Assim, o tempo necessário de permanência do pesquisador no campo está relacionado à qualidade da aprendizagem do pesquisador sobre o fenômeno estudado, independente do campo da etnografia.

Achutti (2004b) relata que em se tratando do trabalho de campo fotoetnográfico, o olhar treinado do antropólogo (pesquisador) deve estar disponibilizado para os necessários períodos de imersão; do contrário, a falta de domínio da técnica ou o fetichismo em relação aos instrumentos de pesquisa poderão leválo à autoria de um trabalho raso, prejudicado na intenção descritiva. Ainda mais, cada fotografia deve ter alguma importância quando 'lida' individualmente e, ao mesmo tempo, deve servir como parte integrante de uma sequência de fotografias que, no seu conjunto, possam vir a compor uma das formas de antropologicamente narrar o que é singular.

Achutti (1997b) ainda alerta que as fotografias realizadas de maneira desordenada, sem uma preocupação de serem reunidas em uma sequência para contar uma história, podem tornar-se apenas uma fonte de informação sobre o campo de pesquisa, sem constituir um discurso organizado sobre o objeto de estudo. $\mathrm{O}$ referido autor 
também alerta que não se pode descuidar, ao longo da leitura, do tamanho escolhido para as imagens, da sua separação em conjuntos, da repetição de algumas fotografias e da disposição das mesmas pelas páginas do livro, pois são importantes componentes para a compreensão narrativa do texto visual proposto pelo autor.

Em uma fotografia estão implicados o domínio técnico e a decisão quanto ao tipo de filme, tipo de câmera, característica da lente, qualidade de luz, enquadramento, forma de revelação e ampliação, etc. Para uma fotografia, esteja ela voltada para reportagem, seja ela utilizada como instrumento de pesquisa ou de difusão, a maioria destas decisões devem ser tomadas no campo, no ato de fotografar. Difícil consertar uma fotografia que tenha sido malfeita, ao contrário do que ocorre com o caderno de notas: mesmo que nele venham a constar anotações precárias quanto ao estilo narrativo, ele poder continuar a ser a fonte originadora de um texto de qualidade (ACHUTTI, 2004b, p. 64).

Segundo Achutti (2004b), o domínio técnico da máquina fotográfica, aliado ao olhar treinado do antropólogo, pode levar à construção de um trabalho fotoetnográfico que venha a ser relevante, não só como mais uma das técnicas de pesquisa de campo, mas também como uma outra forma narrativa, que somada ao texto etnográfico, venha enriquecer e dar mais profundidade à difusão dos resultados obtidos.

A capacidade de visão de conjunto do observador depende da proporção de envolvimento dele em relação ao seu meio ambiente (COLLIER JUNIOR, 1973; BONI; MORESCHI, 2007). Quando o pesquisador consegue estabelecer relações de confiança entre aqueles que pesquisa e se o pesquisador tem, além disso, uma 
sensibilidade treinada, saberá quando e o que pode fotografar. É importante igualmente saber quem pode ver o que, quando se leva de volta as imagens anteriormente captadas (NOVAES, 2012).

Como Achutti não relata detalhadamente o procedimento metodológico, limitando-se nas questões técnicas, o Quadro 1 sugere um protocolo para operação do método fotoetnográfico, baseado em autores da antropologia visual, etnometodologia, análise imagética e pesquisa qualitativa: 


\section{Quadro 1 - Operação do método fotoetnográfico}

\begin{tabular}{|c|c|c|c|}
\hline \multirow{4}{*}{ 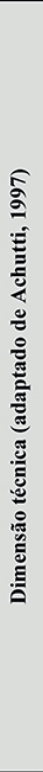 } & $\begin{array}{l}\text { Câmera } \\
\text { Fotográfica }\end{array}$ & $\begin{array}{l}\text { Variam conforme o tamanho do } \\
\text { fotograma que produzem, qualidade, } \\
\text { peso da máquina e o número de } \\
\text { dispositivos de controle que } \\
\text { oferecem. }\end{array}$ & $\begin{array}{l}\text { Fotografias que buscam uma descrição etnográfica de } \\
\text { rituais, de danças, de cenas de sociabilidade em bares } \\
\text { ou casas de jogos, de trabalhos manuais, dentre outros, } \\
\text { são fotografias que demandam bastante agilidade por } \\
\text { parte do pesquisador, além do fato de, geralmente, } \\
\text { ocorrerem em situações de luminosidade limitada. } \\
\text { É necessária a perícia no manuseio. }\end{array}$ \\
\hline & Objetiva & $\begin{array}{l}\text { Objetivas de distância focal acima } \\
\text { de } 50 \mathrm{~mm} \text { são chamadas } \\
\text { teleobjetivas; e abaixo de } 50 \mathrm{~mm} \text {, } \\
\text { são chamadas grande-angulares. } \\
\text { Nas câmeras digitais, esse ajuste } \\
\text { pode ser feito automaticamente, } \\
\text { através da regulagem do zoom, ou } \\
\text { em funções específicas de cada } \\
\text { máquina. }\end{array}$ & $\begin{array}{l}\text { As teleobjetivas são lentes de exclusão. Elas ajudam a } \\
\text { aproximar determinado elemento de uma cena sem ter } \\
\text { que entrar nela, o que evita interferência } \\
\text { comprometedora no trabalho de campo. } \\
\text { As lentes grande-angulares são lentes de inclusão. } \\
\text { Com elas só é possível o recorte em cenas muito } \\
\text { amplas. São ideais quando se quer fazer o registro em } \\
\text { áreas grandes com pouco espaço para o recuo do } \\
\text { fotógrafo, pois esse tipo de lente capta as luzes de uma } \\
\text { cena num ângulo bastante aberto, que pode ultrapassar } \\
\text { os } 180^{\circ} \text {. }\end{array}$ \\
\hline & Acessórios & $\begin{array}{l}\text { Desde acessórios para limpeza das } \\
\text { câmeras e objetivas, malas à prova } \\
\text { de água e calor, bem como opções } \\
\text { de bastante utilidade, tais como: } \\
\text { tripé, bateria e filtro polarizador. }\end{array}$ & $\begin{array}{l}\text { O pesquisador deve estar preparado para condições } \\
\text { inesperadas e adversas. }\end{array}$ \\
\hline & $\begin{array}{c}\text { Película ou } \\
\text { arquivo digital }\end{array}$ & $\begin{array}{l}\text { Diz respeito à forma de publicação } \\
\text { do fotograma e tratamento e arquivo } \\
\text { da imagem. }\end{array}$ & $\begin{array}{l}\text { Ao se optar pela fotografia preto e branco, se está } \\
\text { abrindo mão de uma variável que, muitas vezes, pode } \\
\text { ser importante registrar: a cor das roupas, casas, } \\
\text { objetos, peças de artesanato, ritos, manifestações } \\
\text { artísticas, etc. } \\
\text { Em tempos de fotografia em arquivo digital, é } \\
\text { importante evitar a manipulação da imagem. }\end{array}$ \\
\hline \multirow{6}{*}{ 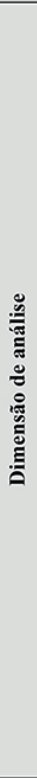 } & $\begin{array}{l}\text { Observação } \\
\text { participante }\end{array}$ & \multicolumn{2}{|c|}{$\begin{array}{l}\text { Envolve a profunda inserção do pesquisador no cotidiano em estudo. Dessa maneira, ele pode } \\
\text { captar conhecimentos amplos ao fazer parte das interações cotidianas. (BLALOCK JR., 1973; } \\
\text { CAVEDON, 1999). } \\
\text { Gold (1958) classificou em quatro tipos básicos: a) Pleno participante: plena participação e } \\
\text { inserção social nos contextos que envolvem o grupo estudado, sem que a identidade e os } \\
\text { propósitos do pesquisador sejam conhecidos por aqueles que ele observa; b) Participante como } \\
\text { observador: o observador se apresenta para o grupo e aqueles que serão observados, revelando } \\
\text { suas intenções e mantendo a ampla inserção no cotidiano investigado; c) Observador como } \\
\text { participante: observação formal, restrita a um contato único e formal com o campo e aquele } \\
\text { que se observa; e d) Pleno observador: o pesquisador permanece afastado dos informantes, } \\
\text { sem se envolver em participação ou qualquer interação social com o grupo investigado. }\end{array}$} \\
\hline & $\begin{array}{l}\text { Notas de campo } \\
\text { e diário de } \\
\text { campo }\end{array}$ & \multicolumn{2}{|c|}{$\begin{array}{l}\text { Registro escrito de eventos sociais relevantes logo após a fotografia, a fim de resgatar quando } \\
\text { preciso. O segundo, trata-se do diário pessoal do pesquisador onde podem ser registradas as } \\
\text { experiências cognitivas e emocionais do trabalho de campo. (ELLIOT; JANKEL-ELLIOT, } \\
\text { 2003). }\end{array}$} \\
\hline & $\begin{array}{l}\text { Planejamento e } \\
\text { entrada cultural }\end{array}$ & \multicolumn{2}{|c|}{$\begin{array}{l}\text { 1) As comunidades devem estar relacionas à pergunta de pesquisa; 2) devem fornecer dados } \\
\text { ricos, ou seja, o mais detalhados e descritivos possiveis; e 3) devem apresentar grande } \\
\text { interação social entre os participantes (BAUER; GASKELL, 2008). }\end{array}$} \\
\hline & Coleta de dados & \multicolumn{2}{|c|}{$\begin{array}{l}\text { 1) os dados coletados diretamente da comunidade pelo pesquisador; e 2) os dados registrados } \\
\text { pelo pesquisador provenientes da observação da comunidade (BAUER; GASKELL, 2008). }\end{array}$} \\
\hline & $\begin{array}{l}\text { Análise de } \\
\text { dados }\end{array}$ & \multicolumn{2}{|c|}{$\begin{array}{l}\text { Examine o que as fotografias trazem de significação; identifique os conhecimentos culturais } \\
\text { aos quais as fotos se referem e são interpretadas. (BAUER; GASKELL, 2008). Que dados } \\
\text { você tem? O que a câmara testemunhou? Estas perguntas podem ser feitas indefinidamente } \\
\text { (COLLIER JR., 1973). Além disso, deve-se construir as estruturas categóricas, servindo-se do } \\
\text { material classificado. }\end{array}$} \\
\hline & Apresentação & \multicolumn{2}{|c|}{$\begin{array}{l}\text { Selecione a forma de apresentação da pesquisa: relatório, mural, exposição, etc. (BAUER; } \\
\text { GASKELL, 2008). O último passo para se transformar a imagem visual em conclusão } \\
\text { cientifica é condensar a evidencia encontrada durante a análise total ou transformar as } \\
\text { variáveis em formato de melhor visualização (COLLIER JR., 1973). }\end{array}$} \\
\hline
\end{tabular}

Fonte: adaptado pelos autores, 2017. 
Na próxima seção, será discutida a aplicação do método fotoetnográfico na Administração a fim de enriquecer - através da descrição e interpretação dos padrões compartilhados de cultura de um grupo social - a análise das organizações.

\section{Uso e Possibilidades de Aplicação do Método Fotoetnográfico na Área de Administração}

O emprego da fotoetnografia na Administração abre um amplo leque de possibilidades, tanto em termos de descobertas que podem enriquecer estudos organizacionais, quanto no avanço de conhecimento em diversos temas específicos de interesse do pesquisador. São poucos os usos do método fotoetnográfico na área. Alguns se limitam a análises de fotografias como um recurso de pesquisa (MENDONÇA; BARBOSA; DURÃO, 2007), mas não etnográfico; outros são mais assertivos e explicitam seu uso no campo de cultura do consumo (COSTA; LEÃO, 2010; LEÃO; COSTA, 2013) e cultura organizacional (CAVEDON, 2005).

Dessa maneira, esta seção se propõe a refletir sobre como o método fotoetnográfico pode ser utilizado na Administração, tendo em vista as particularidades que exprimem o potencial do método. Abaixo estão algumas possibilidades por campo de estudo, sendo eles: cultura organizacional; cultura do consumo; comportamento organizacional; gestão por processos; marketing; gestão de pessoas; dentre outros. 


\section{Cultura organizacional}

Quando se pensa em trazer a antropologia visual para os estudos organizacionais, de modo específico para a temática da cultura organizacional, se quer ampliar a observação sobre o campo, além de "apresentar em imagens dados em que encontrariam dificuldades de serem expressos através de palavras, pois as palavras aprisionam e a imagem liberta, ao permitir um olhar polissêmico, uma 'cadeia flutuante' de significados, podendo o leitor escolher alguns e ignorar outros" (BARTHES, 1990, p. 32).

Mascarenhas (2002) afirma que a antropologia interpretativa advoga por um conceito de cultura essencialmente semiótico, onde os indivíduos ou uma determinada comunidade expressam e tecem suas considerações de acordo com as vivências de seu contexto natural. A antropologia interpretativa tem como objeto de estudo a cultura tomada em pequenos recortes, minuciosamente analisada pelo método etnográfico, tendo como característica uma grande riqueza de detalhes em relação à dinâmica cultural reconhecível a partir dos processos sociais inerentes ao grupo estudado (MASCARENHAS, 2002). Leão e Mello (2007) propõem que a observação das relações dentro das organizações, entre pares ou entre pessoas de diferentes níveis hierárquicos, poderia ser importante para diferentes áreas, além da etnografia. Assim, pode-se pensar numa possibilidade para uma pesquisa fotoetnográfica também.

Achutti (1997b) analisou a cultura organizacional na Biblioteca François Miterrand, através de um percurso fotoetnográfico que levou a descobrir esse espaço juntamente com 
o olhar do fotógrafo. Antes de adentrar nas fotografias, o autor traz uma reflexão sobre seu trabalho de campo nos bastidores da biblioteca, o cotidiano de trabalho dos funcionários, a dificuldade em transpassar do universo público ao que seria o universo privado dos trabalhadores; as negociações envolvidas para realização da etnografia e a própria contextualização das condições de trabalho na biblioteca.

O uso do método fotoetnográfico pode ser pensado para compreender a cultura e os discursos organizacionais, a utilização implícita e explícita de linguagem verbal e não verbal, bem como as interações e a produção de sentidos nas práticas organizacionais. Outros usos possíveis: estabelecimento de forças e poder de barganha nas negociações entre uma organização e seus fornecedores e distribuidores poderia ser analisado sob diferentes perspectivas; relações entre atores sociais e instituições; dominação e poder nas organizações e entre os atores sociais; identidade organizacional, dentre outros. Assim, pode-se perceber um uso interdisciplinar e transversal do método, com diversas possibilidades.

\section{Cultura do Consumo}

Um artigo de Costa e Leão (2010) visou descrever a teia discursiva formada no limiar relacional entre culturas, utilizando uma marca transnacional como veículo de expressão da sociedade ocidental, registrando sua presença nas práticas cotidianas mundanas. Ainda dos mesmos autores, Leão e Costa (2013), outro artigo buscou compreender a sociedade ocidental contemporânea por meio dos discursos estabelecidos entre as culturas global e 
local. Ambos artigos utilizaram o método fotoetnográfico, realizado nas principais vias e suas adjacências da Região Metropolitana do Recife, revelando dois lados de um discurso: a apropriação do espaço urbano pela marca Coca-Cola e de seus signos pela cidade.

No campo da cultura do consumo, além dos estudos citados, é possível pensar no método fotoetnográfico para descrever e interpretar padrões compartilhados de cultura de um grupo social, bem como compreender cultura de massas e promoção de marcas a símbolos culturais complexos. O método pode ser utilizado em investigações relativas a diferenças culturais e sociais, tribos urbanas, estética e identidade social e estilos de vida. Também é possível explorar o consumo e/ou o anticonsumo - seus significados, influências e práticas - envolvendo áreas de conhecimento diversas, tais como a Comunicação Social e Sociologia.

\section{Comportamento Organizacional}

A fotoetnografia poderia permitir o acesso a temas mais delicados que dizem respeito ao comportamento dos indivíduos nas organizações, tais como: conflitos, confiança, poder e autoridade. A observação das relações entre as pessoas das organizações com seus stakeholders ${ }^{1}$ também seria útil para estudos em diversas áreas. Estudos que aprofundem a reflexão sobre o comportamento de indivíduos e interação em grupo nas organizações, bem como estudos que apresentem perspectivas instigantes para a compreensão de práticas de aprendizagem social, são exemplos de possíveis boas

1 O termo stakeholders refere-se aos diversos grupos (funcionários, acionistas, fornecedores, concorrentes, clientes, o Estado, entre outros) com as quais a empresa ou organização se relaciona. 
aplicações do método fotoetnográfico. O emprego da fotoetnografia concederia ao pesquisador a sustentação metodológica requerida para inserir-se no ambiente interno do grupo empresarial, exercitando o estranhamento e o olhar antropológico, identificando e interpretando princípios de solidariedade interna, as formas de manifestação e autoridade e os valores morais.

Outras possibilidades de utilização do método: pesquisas que avancem sobre a contribuição de percepções, emoções, desejo, afeto, valores, crenças e atitudes para compreender o comportamento dos indivíduos enquanto membros do grupo. Temas de fronteira no âmbito dos estudos do comportamento e interações nas organizações são possíveis de serem explorados, bem como possibilidades de extrair sentido nas relações entre os indivíduos e entre o indivíduo e a organização, tais como aspectos: da comunicação, motivação, satisfação, valores no trabalho, comprometimento, formação de equipes de trabalho. Vale salientar que o interesse principal é na estrutura social e a interpretação do significado dos eventos para a cultura do grupo, ou seja, na maneira como o indivíduo se posiciona nas relações sociais. Afinal, a fotoetnografia nos revela tanto uma mensagem conotativa quanto denotativa dessas relações.

Analisando especificamente a aplicação do método fotoetnográfico aos estudos que focalizam o comportamento organizacional, sobretudo sob a ótica dos atores envolvidos e da mudança social por eles gerada, pode-se afirmar que esse método pode fornecer inúmeras contribuições a tais estudos. O trabalho do fotoetnográfo no campo poderia privilegiar a interpretação, focalizando tanto as divergências quanto os compromissos, as interações e as negociações que se formam entre os atores. 


\section{Gestão por Processos}

A abordagem por processos permite melhor especificação do trabalho realizado, o desenvolvimento de procedimentos, a gestão do conhecimento e a melhoria, por meio da análise do trabalho realizado, de modo a identificar oportunidades de aperfeiçoamento.

Melleiro e Gualda (2006) trazem o enfoque avaliativo de resultado em que se observa as falas das gestantes, no qual as mesmas expressam o valor e o impacto dessa experiência, bem como projetam a sua importância para outras mulheres que estejam na mesma fase em que elas se encontram, configurandose, assim, os efeitos da assistência a que essas gestantes estão prestes a receber. Esse tipo de estudo fotoetnográfico permite outra perspectiva e tem diversas finalidades e utilidades: desde servir de fonte de informação para melhoria das condições do local de pré-parto, parto e pós-parto, por exemplo; até entendimento das relações sociais de um hospital (médicos, enfermeiras, auxiliares de limpeza, acompanhantes, pacientes, etc.) ou gestão dos processos internos para melhoria de todo hospital.

\section{Marketing}

A utilização do método fotoetnográfico em marketing para o estudo das propagandas, anúncios e promoções seria bastante relevante e, que, por incrível que pareça, não se encontra na literatura acadêmica. Esse tipo de pesquisa na área pode permitir ao pesquisador identificar determinadas etapas características que são marcantes das mudanças ocorridas, bem como acompanhamento da evolução de determinada tendência social através do tempo. Além 
disso, poderia estudar as relações entre as organizações e os outros atores do ambiente, como competidores, consumidores, clientes, canais, instituições e outros.

Leão e Mello (2007) citam que, para o estudo etnográfico, o marketing poderia analisar a atitude dos funcionários de contato em relação ao seu papel de atendimento. As relações entre empresas e clientes finais poderiam ser importantes para a compreensão de certos fenômenos. Neste caso, a área de marketing poderia acessar como os consumidores significam os diferentes aspectos da administração de marketing das organizações ou a identidade visual da marca e design de produtos. Para esses exemplos, poderia ser utilizado perfeitamente a fotoetnografia como método de pesquisa qualitativa.

\section{Gestão de Pessoas}

Leão e Mello (2007), no artigo 'Apresentando a etnografia da comunicação ao campo da pesquisa em Administração', sugerem que o método etnográfico, no campo de gestão de pessoas, pode analisar a difusão e recepção de políticas organizacionais, satisfação e motivação com o trabalho; a área de comportamento organizacional poderia analisar aspectos relativos a liderança, motivação, variações culturais. Além do que foi citado, podese pensar para a utilização da fotoetnografia: a forma de relação entre as diferentes abordagens em práticas de gestão de pessoas; situações/condições de trabalho - dentre elas o trabalho escravo; comprometimento com a organização; liderança e motivação; clima organizacional; mudança organizacional; relação entre trabalho e relacionamentos; modos de trabalhar e suas consequências no ser 
e no viver; gerenciamento de impressões; e como se externaliza a espiritualidade no ambiente de trabalho e interfere nas relações sociais.

\section{Outros Campos da Administração}

Há a possibilidade de adotar o método fotoetnográfico com a finalidade de interpretar a gestão de serviços públicos por setores específicos, tais como: mobilidade e transporte, saneamento, saúde, educação, segurança pública, atendimento ao cidadão, dentre outras perspectivas da prestação de serviços públicos. Nadja Monnet (2014) utiliza a fotoetnografia para descrever o espaço urbano, por exemplo.

Outrostemasquepodemserpensadosparaadoçãodométodo: observação dos aspectos relativos a poder e institucionalização das normas organizacionais; a história institucional e suas relações com os atores ao longo do tempo; análise organizacional (demonstração do tradicionalismo e burocracia nas organizações, por exemplo); comportamentos éticos das (e nas) organizações; atitudes e competências empreendedoras; práticas do empreendedorismo social e cultural; transferência e compartilhamento do conhecimento. Além desses, a articulação entre o tema redes sociais (off-line) e outros elementos, como: significados, valores, atitudes, status, prestígio e legitimidade e relação das atividades da rede e a história do local, do território e da comunidade.

Essas são algumas possibilidades de aplicação do método fotoetnográfico na área de Administração. Vale salientar que se tratam de sugestões, mais com o intuito de estimular a busca pelo conhecimento a respeito do método, sobretudo seu uso. Como afirma Godoy (2006), é imprescindível compartilhar a perspectiva da 
etnografia ou fotoetnografia (esse último, acrescentado pelos autores) como uma estratégia global de pesquisa, o que requer concebê-la também como uma postura epistemológica do pesquisador.

\section{Considerações Finais}

O objetivo deste ensaio foi discutir o método fotoetnográfico no âmbito da pesquisa em Administração, apresentando conceitos, sua operação e reflexão sobre como poderia ser utilizado na área. A utilização de pesquisas de caráter fotoetnográfico em Administração não só é recente, como é escassa. É possível afirmar que a pouca utilização do método fotoetnográfico na Administração se deve à falta de conhecimento do uso e de suas possibilidades, tendo em vista a variedade de aplicações do método, como visto na seção anterior.

É possível também inferir que a influência da base histórica da Administração em si, centrada nas raízes positivistas e funcionalistas, ainda predomina nas abordagens das pesquisas acadêmicas da área. Essa influência talvez encontre alicerce nas afirmações de Morin (2005) acerca da predominância de certos aspectos na epistemologia da ciência, existe uma certa conveniência em utilizar métodos e técnicas já validados em pesquisas anteriores, fato que promove uma circularidade na produção científica.

O presente ensaio metodológico representa uma importante contribuição não só para a antropologia visual, por apoiar-se na fotografia como uma linguagem capaz de dar conta de uma forma de escritura sobre o real, mas também para a Administração, área com bastante potencial na utilização de métodos qualitativos, sobretudo da fotoetnografia. Fica clara a necessidade de se buscar "diferentes métodos para compreender os diversos fenômenos 
organizacionais e, consequentemente, a importância de adotar métodos mais adequados a cada problema organizacional com que se depara" (LEÃO; MELLO, 2007).

Tem-se como limitação desta pesquisa o fato de ter pouca publicação a respeito, exigindo mais dos pesquisadores na busca de fontes nacionais e internacionais em outras áreas de estudo, bem como exigindo maior tempo para pesquisa, análise e interpretação do conteúdo. As vantagens e desvantagens da fotoetnografia são muito semelhantes à da etnografia tradicional, tais como: alto custo, complexidade de análise, maior tempo para coletar dados relevantes.

O desafio é como levar essa perspectiva metodológica adiante sem retomar, a cada publicação, todo o percurso da antropologia visual, e outras áreas, e sua importância dentro do campo de conhecimento da antropologia, avançando nas discussões. Assim, conclui-se que, mesmo diante dos desafios e limitações aos quais a pesquisa fotoetnográfica está sujeita, esta pode gerar oportunidade de geração de conhecimento relevante na ciência Administrativa.

\section{Referências}

ACHUTTI, Luiz Eduardo Robinson. Fotoetnografia da biblioteca jardim. Porto Alegre: UFRGS, 2004a.

ACHUTTI, Luiz Eduardo Robinson. Fotoetnografia. Porto Alegre: Tomo Editorial Palmarinca, 1997a.

ACHUTTI, Luiz Eduardo Robinson. Fotoetnografia: a profundidade de campo no trabalho de campo e outras questões de ordem técnica. In: KOURY, Mauro Guilherme Pinheiro (Org.). Sociologia da imagem: ensaios críticos. João Pessoa: GREI, 2004b. p. 61-75. 
ACHUTTI, Luiz Eduardo Robinson. Fotoetnografia: um estudo de antropologia visual sobre cotidiano, lixo e trabalho. Porto Alegre: Tomo Editorial Palmarinca, $1997 \mathrm{~b}$.

ANDRADE, Rosane de. Fotografia e antropologia: olhares foradentro. São Paulo: Estação Liberdade/Educ, 2002.

ARNOULD, Eric John.; WALLENDORF, Melanie. Marketoriented ethnography: interpretation building and marketing strategy formulation. Journal of Marketing Research, Chicago, v. 31, p. 484-504, 1994.

BARTHES, Roland. O óbvio e o obtuso. Rio de Janeiro: Nova Fronteira, 1990.

BAUER, Martin W.; GASKELL, George. Pesquisa qualitativa com texto, imagem e som. 7. ed. Petrópolis: Vozes, 2008.

BELK, Russell W.; FISCHER, Eilleen.; KOZINETS, Robert V. Qualitative consumer and marketing research. London: Sage, 2013.

BLALOCK JUNIOR, Hubert Morse. Introdução à pesquisa social. Rio de Janeiro: Zahar, 1973.

BONI, Paulo César; MORESCHI, Bruna Maria. Fotoetnografia: a importância da fotografia para o resgate etnográfico. Doc On-line, Campinas, n. 3, p. 137-157, dez. 2007.

CAVEDON, Neusa Rolita. Fotoetnografia: a união da fotografia com a etnografia no descortinamento dos não ditos organizacionais. Organizações \& Sociedade, Salvador, v. 12, n. 35, out./dez. 2005.

CAVEDON, Neusa Rolita. O método etnográfico em estudos sobre a cultura organizacional: implicações positivas e negativas. 
In: ENCONTRO NACIONAL DE PROGRAMAS DE PÓSGRADUAÇÃO EM ADMINISTRAÇÃO, 23., 1999, Foz do Iguaçu. Anais... Foz do Iguaçu: ANPAD, 1999.

COLLIER JUNIOR, John. Antropologia visual: a fotografia como método de pesquisa. São Paulo: EPU, 1973.

COSTA, Flávia Zimmerle da Nóbrega; LEÃO, André Luiz Maranhão de Souza. Formações discursivas de uma marca global num contexto local: um estudo fotoetnográfico da presença imagética da Coca-Cola numa grande região metropolitana brasileira, inspirado no método arqueológico de Michel Foucault. In: ENCONTRO DE MARKETING DA ANPAD, 4., 2010, Florianópolis. Anais... Florianópolis, 2010. Disponível em: <http:/www.anpad.org.br/diversos/trabalhos/EMA/ ema_2010/2010_EMA56.pdf>. Acesso em: 15 dez. 2016.

FREITAS, G. K. A.; LEÃO, A. L. M. S. Concepção da Netnografia da Comunicação: uma abordagem aplicada à pesquisa em administração. Gestão.Org: Revista Eletrônica de Gestão Organizacional, v. 10, n. 2, p. 211-228, 2012.

GODOLPHIM, Nuno. A fotografia como recurso narrativo: problemas sobre a apropriação da imagem enquanto mensagem antropológica. Horizontes Antropológicos, Porto Alegre, ano 1, n. 2, p. 161-185, jul./set. 1995.

GODOY, Arilda Schmidt. Estudo de caso qualitativo. In: GODOI, Christiane Kleinübing; BANDEIRA-DE-MELLO, Rodrigo; SILVA, Anielson Barbosa (Org.). Pesquisa qualitativa em estudos organizacionais. São Paulo: Saraiva, 2006. p. 115-146.

GOLD, Raymond L. Roles in sociological field observations. Social Forces, Chapel Hill, v. 36, p. 217-223, mar. 1958.

HERITAGE, John C. Ethnomethodology. In: GIDDENS, A.; 
TURNER, J. (Ed.). Social theory today. Cambridge: Polity Press, 1987. p. 224-272.

LEÃO, André Luiz Maranhão de Souza; COSTA, Flávia Zimmerle da Nóbrega. Bidimensionalidade mundana no lado Coca-Cola da vida: um estudo arqueológico fotoetnográfico. Discursos Fotográficos, Londrina, v. 9, p. 139-170, 2013.

LEÃO, André Luiz Maranhão Souza; MELLO, Sérgio Carvalho Benício. Apresentando a etnografia da comunicação ao campo da pesquisa em administração. In: ENCONTRO DE ENSINO E PESQUISA EM ADMINISTRAÇÃO E CONTABILIDADE, 1, 2007, Recife. Anais... Recife, 2007. Disponível em: <http://www. anpad.org.br/admin/pdf/ENEPQ21.pdf>. Acesso em: 5 jul. 2018.

MALINOWSKI, Bronislaw. Journal d'ethnologue. Paris: Seuil, 1985.

MASCARENHAS, André Ofenhejm. Etnografia e cultura organizacional: uma contribuição da antropologia à administração de empresas. Revista de Administração de Empresas, São Paulo, v. 42, n. 2, p. 88-94, abr./jun. 2002.

MELLEIRO, Marta Maria; GUALDA, Dulce Maria Rosa. A abordagem fotoetnográfica na avaliação de serviços de saúde e de enfermagem. Texto \& Contexto em Enfermagem, Florianópolis, v. 15, n. 1 , p. $82-88,2006$.

MENDONÇA, José Ricardo Costa; BARBOSA, Maria Lourdes de Azevedo; DURÃO, André Falcão. Fotografias como um recurso de pesquisa em marketing: o uso de métodos visuais no estudo de organizações de serviços. Revista de Administração Contemporânea, Rio de Janeiro, v. 11, n. 3, p. 57-81, jul./set. 2007.

MONNET, Nadja. Photoethnography of the urban space, or how 
to describe the urban world beyond the words: presentation of a multimedia essay. Visual Ethnography, Matera, v. 3, n. 1, p. 3564 , june 2014.

MORIN, Edgar. Ciência com consciência. Rio de Janeiro: Bertrand Brasil, 2005.

NOVAES, Sylvia Caiuby. A construção de imagens na pesquisa de campo em antropologia. Iluminuras, Porto Alegre, v. 13, n. 31, p. 11-29, jul./dez. 2012.

PINTO, Marcelo de Rezende; BARROS, Leonardo Lemos da Silveira. Em busca de uma trilha interpretativista para a pesquisa do consumidor: uma proposta baseada na fenomenologia, na etnografia e na grounded theory. RAE Eletrônica, São Paulo, v. 7, n. 2, art. 25, jul./dez. 2008. Disponível em: <http:// www.scielo.br/scielo.php?script $=$ sci_arttext\&pid $=$ S1676$56482008000200009 \& \operatorname{lng}=\mathrm{en} \& \mathrm{nrm}=\mathrm{iso} \& \mathrm{t} \operatorname{lng}=\mathrm{pt}>$. Acesso em: 5 jul. 2018.

PROSSER, Jon. Image based on research. London: Falmer Press, 1998.

ROCHA, Everardo; BARROS, Carla. Dimensões culturais do marketing: teoria antropológica, estudos etnográficos e comportamento do consumidor. Revista de Administração de Empresas, São Paulo, v. 46, n. 4, p. 36-47, 2006.

Disponível em: <http://www.scielo.br/scielo.php?script=sci arttext\&pid $=$ S0034-75902006000400005> . Acesso em: 5 jul. 2018.

SAMAIN, Etienne. O fotográfico. 2. ed. São Paulo: Hucitec, 2005.

TEN-HAVE, Paul. Understanding qualitative research and ethnomethodology. London: Sage, 2004. 